\title{
Enhancing Transdermal Delivery of Glimepiride Via Entrapment in Proniosomal Gel
}

\author{
Marwa Helmy Abdallah ${ }^{1,2}$, Shereen Ahmed Sabry' ${ }^{1}$, Azza Ali Hasan ${ }^{\text {** }}$ \\ 'Department of Pharmaceutics and Industrial Pharmacy, Faculty of Pharmacy, Zagazig University, Zagazig, EGYPT. \\ 2Department of Pharmaceutics, College of Pharmacy, Hail University, KSA.
}

\begin{abstract}
Objective: The aim of this study is to formulate and evaluate proniosomal gel formulations as transdermal delivery systems of glimepiride (GM) to improve its therapeutic efficacy. Methods: Proniosomal formulations have been prepared using different types of non-ionic surfactants with cholesterol in different molar ratios. Proniosomal gel; $\mathrm{PN}_{16}$ (Span 60, Tween 60, Cholesterol; 35:35:30 molar ratio) that exhibits maximum EE \% (94.01 \pm 0.88) and most prolonged release was chosen for ex-vivo skin permeation and in-vivo hypoglycemic activity studies. Results: Proniosomal gel produced better permeation through rabbit skin than HPMC niosomal gel and HPMC gel. The pharmacokinetic parameters; time of maximum response $\left(T_{\max }\right)$, $\%$ reduction in blood glucose concentration and area above the blood glucose levels-time curve (AAC) of proniosomal gel were studied. Proniosomal gel showed a controlled release behavior and a significantly higher hypoglycemic activity $(65.34 \pm 6.54 \%)$. Conclusion: It is evident from this
\end{abstract}

study that proniosomal gel can act as an alternative approach for enhancing transdermal delivery of GM.

Key words: Glimepiride, Hypoglycemic activity, Nonionic surfactants, Proniosomal gel, Area above the blood glucose levels-time curve.

Correspondence :

Azza Ali Hasan,

Department of Pharmaceutics and Industrial Pharmacy, Faculty of Pharmacy, Zagazig University, Zagazig, EGYPT.

Phone no: 002/01120222772

E-mail: azzahasan_7@hotmail.com

DOI: 10.5530/jyp.2016.4.8

\section{INTRODUCTION}

Glimepiride (GM) is used for the treatment of type 2 diabetes. It is one of the third generation sulfonylurea drug having a poor aqueous solubility, slow dissolution rate. ${ }^{1}$ Due to its short elimination half-life $(2-3 \mathrm{~h})$ repeated doses are required which may cause different side effects such as headache and gastrointestinal disorders. ${ }^{2}$ There are a number of formulation approaches to resolve the problems of low solubility and low bioavailability. Proniosomes technology offers novel solution for poorly soluble drugs to enhance its bioavailability hence, avoid repeated dosing. A novel transdermal GM loaded proniosomal gel was developed to improve its therapeutic efficacy.

Proniosomes are dry formulation of water soluble carrier particles that are coated with non-ionic surfactant. They are rehydrated to form niosomal dispersion immediately before use on agitation in hot aqueous media within minutes. ${ }^{3}$ For the transdermal delivery of the drug proniosomes were formulated as gel like concentrated niosomes suitable for topical application. ${ }^{4}$ Regarding the applications of transdermal proniosomes in diabetes: Gupta et al. concluded that metformin proniosomal gel is promising prolonged drug delivery system. ${ }^{5}$

The Aim of the present study was to prepare and evaluate transdermal GM loaded proniosomal gel. Drug entrapment efficiency, release profiles, ex-vivo skin permeation and in-vivo hypoglycemic activity were evaluated.

\section{MATERIALS AND METHODS}

Glimepiride (GM) was a gift sample kindly supplied by Sigma Pharmaceutical Industries (S.P.I) SAE, Mubarak $1^{\text {st }}$ Industrial Zone, Monufia, Egypt. Span 20, Span 60, cholesterol, poloxamer 407 and sodium azide were purchased from Sigma Chemical Co., St. Louis, MO, USA. HPMC was obtained from El-Nile pharmaceutical company, Cairo, Egypt.
Tween 20, Tween 60, ethanol and propylene glycol were purchased from El-Nasr Pharmaceutical Chemical Co., Cairo, Egypt.

\section{Preparation of Glimepiride loaded proniosomal gel}

Proniosomal gels were prepared by co-acervation phase separation method. ${ }^{6}$ Surfactant and cholesterol were mixed in a dry, clean and wide mouthed glass vials in different molar ratios to make $1000 \mu \mathrm{mol}$ total lipids. About $400 \mathrm{mg}$ propylene glycol and absolute ethanol mixture (1:1) was added then all ingredients were mixed well and open end of the glass vials were tightly closed to prevent any loss of solvent. Then, vials were warmed in water bath at $55-60^{\circ} \mathrm{C}$ for about $5 \mathrm{~min}$ while shaking until complete dissolution of lipids. The drug $(10 \mathrm{mg} / \mathrm{ml})$ was then added to the lipid mixture while warming in a water bath. Then, the aqueous phase (PBS, pH 7.4) containing $2 \%$ sodium lauryl sulphate (SLS) as solubilizer warmed to $60^{\circ} \mathrm{C}$ was then added. The obtained mixtures were allowed to cool down at room temperature. The composition of proniosomal gel formulations is listed in Table 1 .

\section{Preparation of niosomes}

Niosomes were prepared by hydration of the prepared proniosomal gels.? Glass vials containing GM loaded proniosomal gels were heated to melting and certain volume of PBS heated to about $60^{\circ} \mathrm{C}$ was added into each vial to obtain niosomal dispersion. The vials were vortexed for $2 \mathrm{~min}$. The final volume was adjusted to $10 \mathrm{ml}$ by the same buffer.

\section{Determination of Glimepiride entrapment efficiency percentage}

One milliliter niosomal samples obtained after hydration of proniosomal gels were centrifuged at $14,000 \mathrm{rpm}$ for $1 \mathrm{~h}$ at $4^{\circ} \mathrm{C}$ using Centrifuge. ${ }^{8}$ The supernatant containing the free drug was decanted. Niosomal pellets were re-suspended in PBS containing 2\% SLS and re-centrifuged again. This washing procedure was repeated twice, then the collected superna- 
tant was assayed spectrophotometrically at $230 \mathrm{~nm}$ using PBS containing $2 \%$ SLS as a blank by UV-Vis Spectrophotometer. The EE was calculated according to the following equation:

$$
\text { Glim epiride EE } \%=\frac{\text { Amount of GM entrapped }}{\text { Total amount of GM }} \times 100
$$

\section{Formulation of Glimepiride gels}

GM gels $0.5 \% \mathrm{w} / \mathrm{w}$ were formulated using two different gelling agents; HPMC (2\%) and poloxamer 407 (15\%). The weighed amount of gelling agent powder was sprinkled gently on $100 \mathrm{ml}$ PBS containing $500 \mathrm{mg}$ of the drug and stirred at $500 \mathrm{rpm}$ using magnetic stirrer. Stirring was continued until a thin dispersion was formed. ${ }^{9}$ The prepared dispersion was kept overnight in the refrigerator until homogenous gel was obtained.

\section{Formulation of Glimepiride niosomal gels}

Niosomal gels loaded with GM were prepared by replacing a portion of the PBS by concentrated niosomal dispersion loaded with the required quantity of drug and the procedure was completed as previously mentioned. ${ }^{10}$ The final lipid concentration per $20 \mathrm{~g}$ of the gel formulation was $50 \mu \mathrm{mol} / \mathrm{g}$.

\section{Viscosity measurement}

The viscosity of the prepared gel formulations was determined at room temperature using Viscostar viscometer using spindle R5 at $2 \mathrm{rpm} .{ }^{11}$

\section{Microscopic examination}

Small amounts of the proniosomal gel and its hydrated form were spread on a glass slide as a thin layer and examined for the structure of the prepared gel using an ordinary light microscope with magnification power of $40 \mathrm{x} .{ }^{12}$

\section{Backing membrane reservoirs}

Circular plastic holders with a $2.9 \mathrm{~cm}$ inner diameter were used as backing membrane reservoirs for proniosomal gels.

\section{In-vitro release study through cellophane membrane}

The in-vitro release of GM from different formulations was determined by using a diffusion cell fabricated in our laboratory. The cell consisted of a hollow glass tube of internal diameter of $2.9 \mathrm{~cm}$. The backing membrane reservoirs (donor) containing one gram of each formulation (containing $5 \mathrm{mg}$ of GM) were attached to the glass tubes at one end and covered with semi-permeable membranes with the aid of rubber bands. The tubes were attached to the stem of the dissolution apparatus by using parafilm to avoid water evaporation. The tubes were allowed to stir at $100 \mathrm{rpm}$ in $250 \mathrm{ml}$ of PBS containing $2 \%$ SLS maintained at $37 \pm 0.5^{\circ} \mathrm{C} .{ }^{13}$ In order to determine the release of GM from niosomal dispersion, the cellophane membranes were attached directly to one end of the tubes and certain volumes of niosomal dispersion containing $5 \mathrm{mg}$ of GM were used. Three $\mathrm{ml}$ samples were withdrawn at specified time intervals for $24 \mathrm{~h}$ and replaced with fresh buffer solution. The samples were analyzed spectrophotometrically at $230 \mathrm{~nm}$.

\section{Ex-vivo drug permeation studies through rabbit skin}

Abdominal full-thickness skins of white Albino male rabbits were used. The skin was carefully removed from animals and prepared for experiment. The prepared skin samples were mounted on the receptor compartment with the stratum corneum facing upward towards the donor compartment and the dermal facing downward. The receptor compartment was then filled with $250 \mathrm{ml}$ of PBS containing $2 \%$ SLS and $0.02 \%$ sodium azide as preservatives and maintained at $37 \pm 0.5^{\circ} \mathrm{C}$. The procedure was completed as previously mentioned. GM steady state transdermal flux $\left(\mathrm{J}_{\mathrm{ss}}\right)$ and lag time for each formulation were calculated. Permeability coefficient $\left(\mathrm{K}_{\mathrm{p}}\right)$ was calculated using the following equation: $\mathrm{k}_{\mathrm{p}}=\mathrm{J}_{\mathrm{SS}} / \mathrm{C}_{\mathrm{o}}$ where, $\mathrm{C}_{\mathrm{o}}$ is the initial drug concentration in the donor. ${ }^{9}$

\section{In-vivo studies}

\section{Selection of animals}

Healthy albino-Wistar male rats, weighing about 200-250 g were used. Rats were obtained from Faculty of Veterinary Medicine, Zagazig University, animal breeding center, Egypt and treated according to Ethical committee of animal handling in Zagazig University "ECAHZU". The animals were housed under standard conditions, maintained on a $12-\mathrm{h}$ light/dark cycle and had free access to food and water up to the time of experimentation. The animals were acclimatized to the laboratory environment $1 \mathrm{~h}$ before the experiments. The blood glucose level was determined for all rats and the fasting blood glucose level (BGL) for rats was (50-80 mg/dl).

\section{Experimental induction of diabetes}

Induction of diabetes was done according to the method employed by Rajaram, 2013. ${ }^{14}$ The rats were injected with alloxan monohydrate freshly dissolved in saline at a dose of $120 \mathrm{mg} / \mathrm{kg}$ intraperitoneally. Rats with fasting glucose ranging from $180-220 \mathrm{mg} / \mathrm{dl}$ were considered diabetic and were used in the experiment. ${ }^{15}$

\section{Experimental Design}

About $6.61 \mathrm{~cm}^{2}$ of skin on the dorsal side of the rat was shaved and then washed with distilled water on the previous day of the experiment. Four groups of wistar rats ( 5 in each group) fasted overnight prior to the experiments were used for the study. After collecting zero hour blood samples, rats were divided into four groups (5 in each group):

Group I: Diabetic rats treated with 2\% HPMC gel base without drug. Group II: Diabetic rats treated with GM suspension prepared in distilled water with the aid of gum acacia orally in a dose of $4 \mathrm{mg} / \mathrm{kg}$ body weight. ${ }^{16}$ Group III: Diabetic rats transdermally treated with $2 \%$ HPMC gel loaded with GM. Group IV: Diabetic rats transdermally treated with proniosomal gel loaded with GM.

Blood sample were collected from tail vein for glucose estimation at $0,1,2,3,4,6,8$, and $24 \mathrm{~h}$ intervals. BLG was determined by using blood glucose measuring instrument One Touch ltra (Lifescan, Inc. Milpitas, CA 95035 U.S.A.) and percentage reduction in blood glucose level was calculated.

\section{Statistical analysis}

Data were expressed as mean \pm SD (standard deviation). The significance was determined by ANOVA. $\mathrm{P}<0.05$ is considered statistically significant.

\section{RESULTS AND DISCUSSION}

\section{Formulation of proniosomal gel}

Span 20 is liquid at room temperature as it has low phase transition temperature ${ }^{17}\left(\mathrm{Tc}=16^{\circ} \mathrm{C}\right)$ and cannot form gels at lower concentrations of Chol, Table 1. Proniosomal gel containing Span 20 will start to be formed at Chol molar percent of 30\%. Since Span 20 is less hydrophobic $(\mathrm{HLB}=8.6)$, it produced proniosomal liquids of one phase at Chol concentrations below $30 \%$. On the other hand, Span 60 produced white creamy gels like appearance in the presence or absence of Chol as it has high $\left(\mathrm{Tc}=53^{\circ} \mathrm{C}\right)$ and are solids at room temperature. ${ }^{17}$ No gel was 
Abdallah et al.: Enhancing Transdermal Delivery of Glimepiride Via Entrapment In Proniosomal Gel

\begin{tabular}{|c|c|c|c|c|c|}
\hline $\begin{array}{l}\text { Batch } \\
\text { Code }\end{array}$ & Surfactant type & $\begin{array}{c}\text { Chol } \\
\text { Molar \% }\end{array}$ & Surfactant: Chol weight (g) & Appearance & $\mathrm{EE} \% \pm \mathrm{SD}$ \\
\hline \multirow{15}{*}{$\begin{array}{l}\mathrm{PN}_{1} \\
\mathrm{PN}_{2} \\
\mathrm{PN}_{3} \\
\mathrm{PN}_{4} \\
\mathrm{PN}_{5} \\
\mathrm{PN}_{6} \\
\mathrm{PN}_{7} \\
\mathrm{PN}_{8} \\
\mathrm{PN}_{9} \\
\mathrm{PN}_{10} \\
\mathrm{PN}_{11} \\
\mathrm{PN}_{12} \\
\mathrm{PN}_{13} \\
\mathrm{PN}_{14} \\
\mathrm{PN}_{15}\end{array}$} & \multirow{2}{*}{$\begin{array}{l}\text { Span } 20 \\
\text { Span } 20\end{array}$} & 0 & $0.347: 0.00$ & One phase liquid & $55.68 \pm 1.08$ \\
\hline & & 10 & $0.312: 0.039$ & One phase liquid & $56.84 \pm 1.52$ \\
\hline & \multirow{2}{*}{$\begin{array}{l}\text { Span } 20 \\
\text { Span } 20\end{array}$} & 20 & $0.277: 0.077$ & One phase liquid & $58.14 \pm 1.27$ \\
\hline & & 30 & $0.243: 0.116$ & Transparent gel & $60.15 \pm 1.79$ \\
\hline & $\begin{array}{l}\text { Span } 20 \\
\text { Span } 20\end{array}$ & 40 & $0.208: 0.155$ & Translucent gel & $62.74 \pm 1.23$ \\
\hline & $\begin{array}{l}\text { Span } 20 \\
\text { Span } 20\end{array}$ & 50 & 0.173:0.193 & Translucent gel & $64.39 \pm 0.89$ \\
\hline & \multirow{2}{*}{$\begin{array}{l}\text { Span } 20 \\
\text { Span } 60\end{array}$} & 0 & $0.431: 0.00$ & White creamy gel & $65.16 \pm 0.68$ \\
\hline & & 10 & $0.388: 0.039$ & White creamy gel & $71.01 \pm 1.11$ \\
\hline & $\begin{array}{l}\text { Span } 60 \\
\text { Span } 60\end{array}$ & 20 & $0.345: 0.077$ & White creamy gel & $72.89 \pm 1.40$ \\
\hline & $\begin{array}{l}\text { Span } 60 \\
\text { Span } 60\end{array}$ & 30 & $0.302: 0.116$ & White creamy gel & $75.29 \pm 1.36$ \\
\hline & $\begin{array}{l}\text { Span } 60 \\
\text { Span } 60\end{array}$ & 40 & 0.259:0.155 & White creamy gel & $73.75 \pm 2.12$ \\
\hline & $\begin{array}{l}\text { Span } 60 \\
\text { Span } 60\end{array}$ & 50 & $0.216: 0.193$ & White creamy gel & $64.80 \pm 1.25$ \\
\hline & Tween 20 & 30 & $0.366: 0.116$ & One phase viscous liquid & $36.89 \pm 1.65$ \\
\hline & $\begin{array}{l}\text { Iween } 20 \\
\text { Tween } 60\end{array}$ & 30 & 0.454:0.116 & One phase viscous liquid & $42.57 \pm 1.53$ \\
\hline & $\begin{array}{l}1 \text { ween } 60 \\
\text { Span60:Tween } 20(1: 1)\end{array}$ & 30 & 0.151:0.183:0.116 & White creamy gel & $85.82 \pm 1.91$ \\
\hline $\mathrm{PN}_{16}$ & Span60:Tween $60(1: 1)$ & 30 & $0.151: 0.227: 0.116$ & White creamy gel & $94.01 \pm 0.88$ \\
\hline
\end{tabular}

Each result is the mean of 3 determinations \pm standard deviation (S.D).

Table 2: Viscosity measurements of the prepared formulations

\begin{tabular}{ccccc}
\hline Formulation & $\begin{array}{c}\text { HPMC } \\
\text { Gel }\end{array}$ & $\begin{array}{c}\text { Poloxamer } \\
\text { Gel }\end{array}$ & HPMC niosomal gel & $\begin{array}{c}\text { Poloxamer niosomal } \\
\text { gel }\end{array}$ \\
\hline Viscosity & $3108 \pm 151 \mathrm{cPs}$ & $5687 \pm 209 \mathrm{cPs}$ & $3232 \pm 175 \mathrm{cPs}$ & $5765 \pm 195 \mathrm{cPs}$ \\
\hline
\end{tabular}

Each result is the mean of 3 determinations \pm standard deviation (S.D).

Table 3: Permeation parameters of GM across abdominal rabbit skin

\begin{tabular}{cccc}
\hline & $\begin{array}{c}\text { Steady-state transdermal } \\
\text { flux }\left(\mathrm{J}_{\mathrm{ss}}\right)\left(\boldsymbol{\mu g} / \mathrm{cm}^{2} . \mathbf{h}\right)\end{array}$ & $\begin{array}{c}\text { Permeability coefficient }\left(\mathbf{k}_{\mathrm{p}}\right) \\
\left(\mathrm{cm} / \mathrm{h}^{*} \mathbf{1 0}^{-3}\right) \\
\pm \text { S.D. }\end{array}$ & Lag time $(\mathbf{h})$ \\
\hline Formulation. & $25.13 \pm 2.96$ & $5.03 \pm 2.37$ & 0.801 \\
HPMC gel & $29.67 \pm 1.75$ & $5.93 \pm 0.59$ & 0.423 \\
HPMC niosomal gel & $36.54 \pm 3.67$ & $7.31 \pm 3.73$ & 0.245 \\
Proniosomal gel & &
\end{tabular}

Each result is the mean value \pm S.D. $(n=3)$.

obtained from Tweens $(20,60)$, but when Tween 20 or Tween 60 mixed with Span 60, it produced white creamy proniosomal gels.

\section{Morphology of the prepared formulations}

Figure 1 represents the photomicrograph of proniosomal gel $\left(\mathrm{PN}_{10}\right)$ and its niosomal dispersion. Niosomes were spherical in shape. On the other hand, proniosomal gel is formed of floccules of small vesculating particles which have a creamy opaque appearance. ${ }^{18}$

\section{Entrapment efficiency}

The EE \% of different formulations followed the order Span 60> Span $20>$ Tween $60>$ Tween 20 as shown in Table 1 . The results are dissimilar to those reported by Mohawed et al. who found that the clomipramine EE of different surfactants could be ranked as follows: Tween $60>$ Span $60>$ Tween 20> Span 20. ${ }^{19}$ The significant increase $(\mathrm{P}<0.05)$ in $\mathrm{EE} \%$ of Span 60 proniosomes may be due to the solid nature, hydrophobicity and high Tc of Span 60 compared to Span 20. This could also be attributed to the structure of Span 60 which has the longest saturated chain length $\left(\mathrm{C}_{18}\right)$ among all Span series. ${ }^{20}$ Table 1 shows that, the EE of proniosomes formed from Span 20 and Span 60 was found high compared with proniosomes prepared from Tween. Most of surfactants used to make niosomal vesicles such as Spans have a low aqueous solubility. However, freely soluble non-ionic surfactants such as Tweens can form the micelles on hydration in the presence of Chol. ${ }^{21}$

For Span 20 proniosomes EE\% of GM was increased significantly $(\mathrm{P}<0.05)$ with increasing Chol concentration from $0 \%$ to $50 \%$. Above the phase transition temperature, Chol had the ability to make the membrane more ordered and abolished the gel to liquid phase transition of niosomal system producing niosomes that are less leaky and less permeable. $^{22}$

Also, Results show that GM EE\% increased by Chol addition in case of Span 60 proniosomes when Chol concentration increased to $30 \%$. Then, 

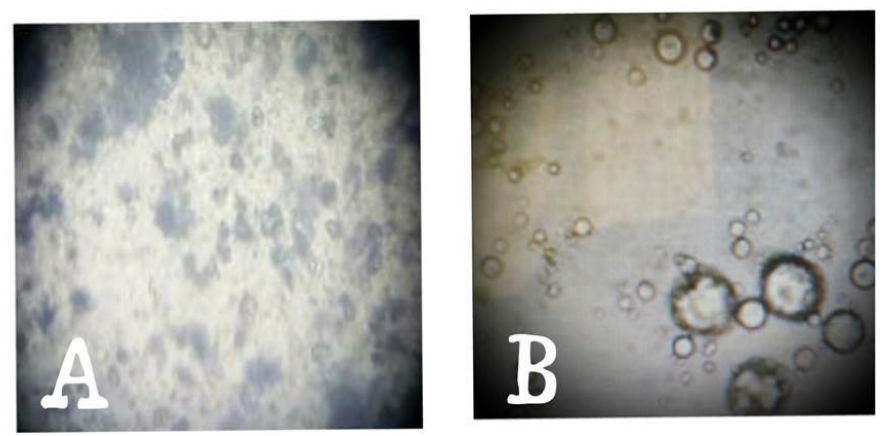

Figure 1: Micrographs (magnification power is 40X) of (A) Proniosomal gel (B) Corresponding niosomal dispersion.

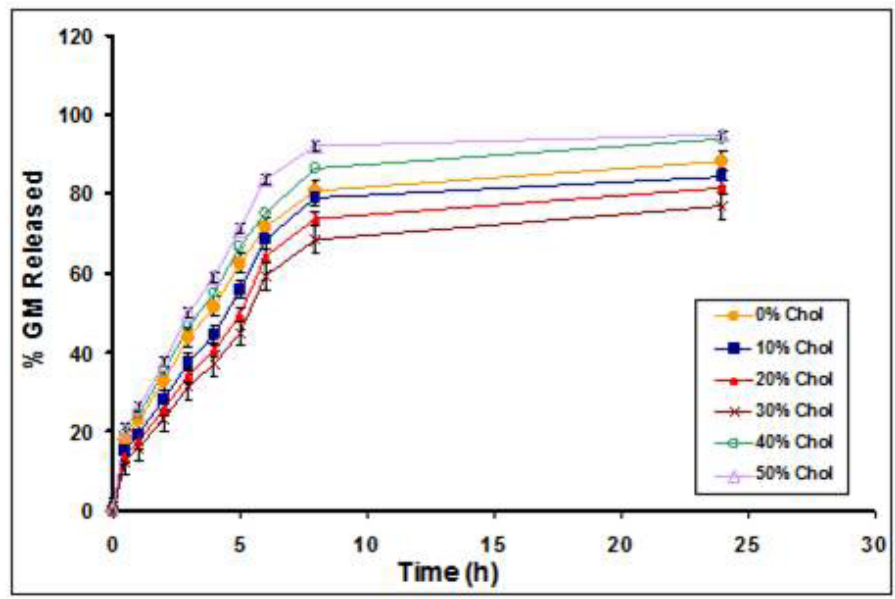

Figure 2: Effect of Chol concentration on in-vitro release of GM from Span 60 proniosomes derived niosomes.

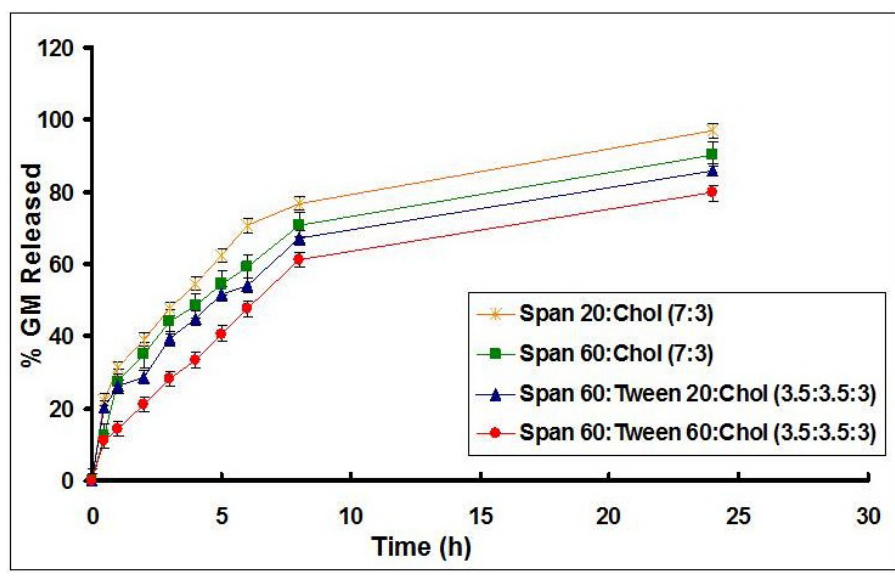

Figure 3: Effect of lipid composition on in-vitro release of GM from different formulations.

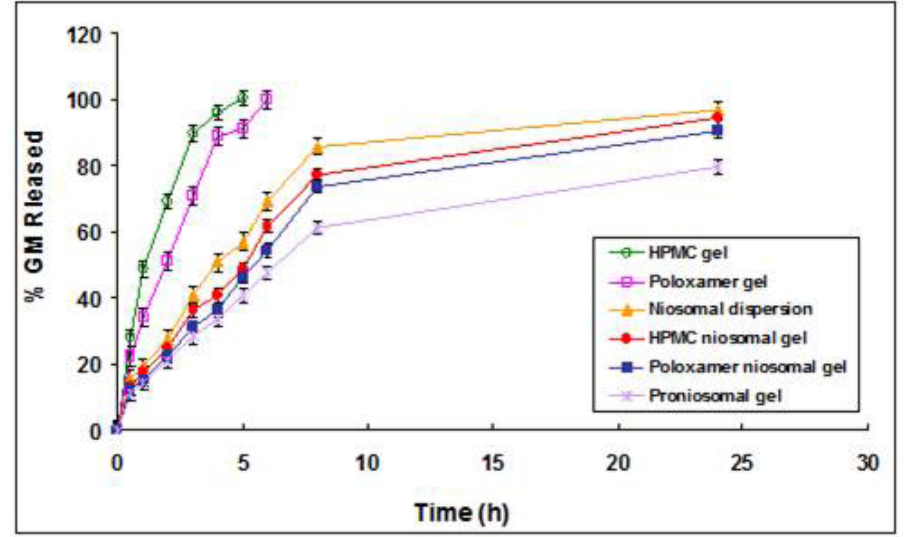

Figure 4: In-vitro release of GM from different formulations across cellophane membrane compared to proniosomal gel.

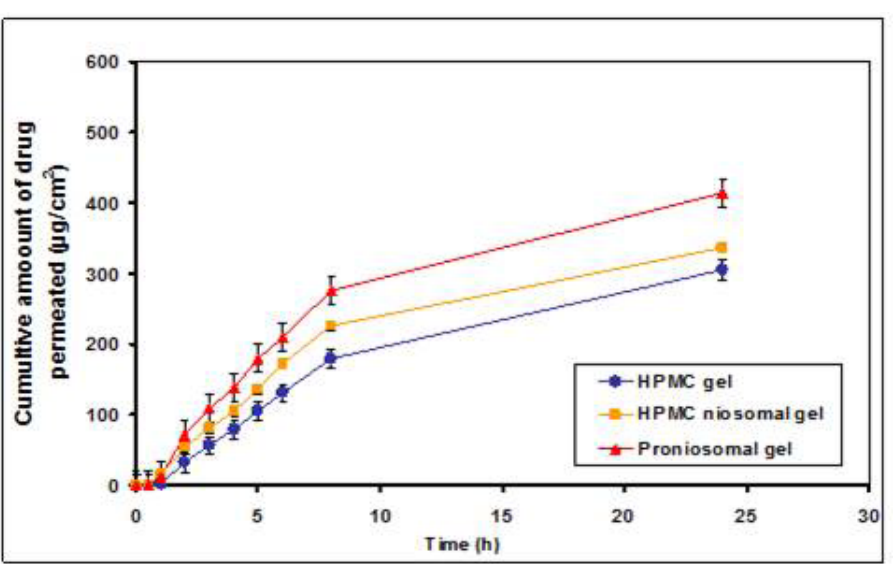

Figure 5: Permeability studies of GM from HPMC gel, HPMC niosomal gel and proniosomal gel across abdominal rabbit skin.

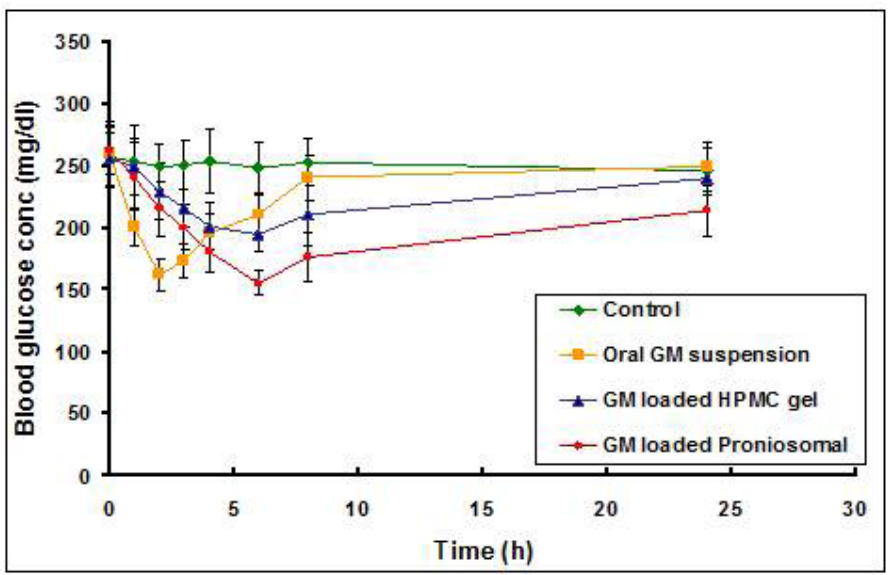

Figure 6: Blood glucose concentration after administration of different GM formulations. 
further increase in Chol concentration led to decreased EE\% of GM. This result could be attributed to competition between drug and Chol for packing in the limited sites in the bilayer structure of niosomes. ${ }^{23}$

Results indicated that proniosomes prepared from a mixture of Span 60 with Tween $(1: 1)$ resulted in a significant increase in the EE \% $(\mathrm{P}<0.05)$. This could be attributed to the larger vesicles size which resulted from the lower hydrophobicity of the mixture of Span 60 and Tween. ${ }^{22}$ This effect may be also related to the increase in the membrane rigidity and formation of less leaky niosomal vesicles upon using mixed surfactants. ${ }^{24}$ Proniosomes prepared from a mixture of Span 60 and Tween 60 had the highest EE \% followed by those prepared from a mixture of Span 60 and Tween 20.

\section{In-vitro release studies}

Figure 2 showed that, \% drug released at $6 \mathrm{~h}$ was significantly decreased $(\mathrm{P}<0.05)$ as Chol concentration increased from $0 \%$ to $30 \%$, which is due to membrane stabilizing ability of Chol. However, further increase in Chol molar ratio starts disrupting the regular linear bilayerd structure of the vesicular membrane leading to increase the drug release rate. ${ }^{25}$

Figure 3 showed that the rate of release of GM from the proniosomal gel prepared from Span $60\left(\mathrm{PN}_{10}\right)$ was lower than Span 20 proniosomal gel $\left(\mathrm{PN}_{4}\right)$. This was attributed to higher Tc of Span 60 than that of Span 20. ${ }^{22}$ Moreover, proniosomes prepared from a mixture of Span 60 and Tweens showed a greater decrease in the in-vitro release of GM. The proniosomal gel formulation $\left(\mathrm{PN}_{16}\right)$ which prepared from Span 60, Tween 60 and Chol (35:35:30) molar ratio showed the highest EE\% and in-vitro prolonged release of drug was chosen for further studies.

Figure 4 showed that, the percentage drug released from HPMC gel was significantly $(\mathrm{P}=0.003)$ higher than that released from poloxamer gel. This may be due to lower viscosities of HPMC compared to poloxamer gels as shown in Table 2. Results also showed that, the drug release from different vehicles showed the following order: polymeric gels $>$ niosomal dispersion $>$ niosomal gel> proniosomal gel. It was demonstrated that incorporation of drug into niosomes resulted in retardation in drug release in case of niosomal dispersion which was further delayed in case of niosomal gel due to presences of gelling agents which form an additional diffusion barrier to drug release. ${ }^{[19]}$ The slower release of drug from niosomal gel formulations may be due to drug encapsulation into vesicles (micro-reservoirs) providing prolonged drug release rate. ${ }^{10}$ The proniosomal gel $\left(\mathrm{PN}_{16}\right)$ gave the lowest drug release among the tested formulations (about $47.5 \pm 1.25 \%$ after $6 \mathrm{~h}$ ). This could be related to the condensed vesicular structure composed of Span 60, Tween 60 and Chol (35:35:30), which is considered a great barrier to drug diffusion and a retardant to its release. The delayed release from proniosomal gel formulation is due to slow release of drug from proniosomes and this may be attributed to the need of proniosomes for a time to be hydrated to form niosomal vesicles before starting release of drug across the cellophane membrane.

\section{Ex-vivo permeability studies}

Figure 5 showed that HPMC niosomal gel resulted in a significant increase in the amount of drug permeated through the skin $(\mathrm{P}=0.04)$, compared to that permeated from HPMC gel. This increase may be related to the action of non-ionic surfactant as penetration enhancer for the drug and the solubilization of lipids within the stratum corneum. ${ }^{10}$ Also, the amount of drug permeated from proniosomal gel was significantly higher than that permeated from niosomal gel $(\mathrm{P}=0.03)$. The superiority of proniosomal gel can be explained on the basis that, the former contained high ethanol content which was diluted in case of niosomes. ${ }^{25}$ It was concluded that, amount of drug permeated through the skin was completely different from that obtained from release experiments through cellophane membranes. The lower permeability of GM across rabbit skin in comparison to cellophane membrane may be related to the barrier properties of skin which hinder drug diffusion rates. ${ }^{10}$

Results demonstrated that, the obtained transdermal flux values were significantly higher in the case of vesicular formulations $(\mathrm{P}=0.003)$. The increase in transdermal flux was associated with a reduction in the lag time, Table 3. The J of GM from proniosomal gel and niosomal gel was 1.45 and 1.18 fold greater than that from HPMC gel, respectively. Also, the reduction in the lag time after application of vesicular gels indicates increased diffusivity and supports skin penetration enhancement of components which suggested a reduction in the barrier nature of skin. ${ }^{26}$ So, Proniosomal gel $\left(\mathrm{PN}_{16}\right)$ formulation was selected for further in-vivo hypoglycemic study due to its higher $\mathrm{EE} \%$ and the enhanced ex-vivo permeation through the skin.

\section{Hypoglycemic activity study}

In-vivo evaluation of the selected formulation was carried out in alloxan induced diabetic wistar rats by measuring hypoglycemic effect produced after transdermal administration of GM loaded proniosomal gel in comparison to GM (pure drug) at same dose either orally or transdermally.

Figure 6 revealed that oral administration of GM suspension produced rapid and significant lowering in the BGL $(\mathrm{P}=0.003)$. The maximum hypoglycemic activity of about $36.75 \pm 3.19 \%(94.71 \pm 15.59 \mathrm{mg} / \mathrm{dl}$, reduction in BGL) was observed after $2 \mathrm{~h}$ (Tmax). On the other hand, group 4 which treated transdermally with GM loaded proniosomal gel, showed slow hypoglycemic effect and the maximum reduction in the BGL appeared after $6 \mathrm{~h}$ (Tmax). The hypoglycemic activity was extended to $24 \mathrm{~h}$ by transdermal administration of proniosomal gel loaded with GM compared with the oral administration of GM suspension which terminated after 6 h. $^{27}$

Proniosomal GM gel application resulted in $65.34 \pm 6.54 \%(101.68 \pm$ $15.88 \mathrm{mg} / \mathrm{dl}$, reduction in BGL) after $6 \mathrm{~h}$ while the inhibition in the BGL produced by the application of GM loaded HPMC gel was $31.71 \pm$ $5.15 \%$ after $6 \mathrm{~h}$. The obtained hypoglycemic activity difference between GM loaded proniosomal gel and GM loaded HPMC gel was around two folds. The results confirm the fact that a significant amount of GM was delivered from the proniosomal gel through rat skin to induce the hypoglycemic effect, so it was concluded that proniosomes enhanced drug delivery through the skin, thereby enhance the pharmacological effect. $^{28}$

The area above the BGL-time curve over $24 \mathrm{~h}\left(\mathrm{AAC}_{0-24}\right)$ after transdermal administration of GM loaded proniosomal gel was found to be $(\sim 1599.2$ mg.h/dl), $\sim 2$ fold higher than transdermal administration of GM loaded HPMC gel $(\sim 825.9 \mathrm{mg} . \mathrm{h} / \mathrm{dl})$ and oral administration of GM suspension ( 686.98 mg.h/dl).

\section{CONCLUSION}

This paper has shown that Glimepiride can be entrapped in proniosomal gel with high efficiency providing a means to deliver GM transdermally. The experimental findings show that either fusion of the vesicles with the intercellular lipid of the stratum corneum and direct transfer of drug from vesicles to the skin and/or the penetration enhancement effect of the non-ionic surfactants may contribute to the mechanism of drug permeation enhancement by proniosomal formulations.

\section{CONFLICT OF INTEREST}

The authors declare no conflict of interest. 


\section{ABBREVIATIONS USED}

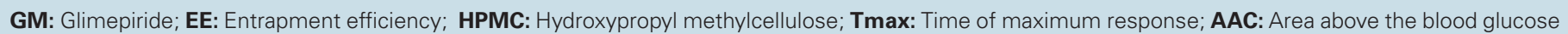
levels-time curve.

\section{REFERENCES}

1. Davis SN. The role of Glimepiride in the effective management of Type 2 diabetes. J Diabetes Complicat. 2004;18(6):367-76.

2. Mriller G, Hartz D, Printer J, Okonomopulos R, Kramer W. Differential interaction of Glimepiride and glibenclamide with the/3-cell sulfonylurea receptor. I. Binding characteristics. Biochim Biophys Acta. 1994;1191(2):267-77.

3. Hu C, Rhodes DG. Proniosomes: A novel drug carrier preparation. Int J Pharm. 2000; 206(1):110-22

4. EI Maghraby GM, Williams AC. Vesicular systems for delivering conventiona small organic molecules and larger macromolecules to and through human skin. Expert Opin Drug Deliv. 2009;6(2):149-63.

5. Gupta N, Khan M, Loona S. Preparation and characterization of metformin proniosomal gel for treatment of diabetes mellitus. Int J Pharma Sci Rev Res. 2012;15(2):108-14

6. Nanda S, Saroha K, Sharma B. Formulation, evaluation and optimization of transdermal gel of ketorolac tromethamine using face centered central composite design. Int J Pharm Pharm Sci. 2014;6(4):133-9

7. Farooqui N, Jaiswal V, Kar M. A Review on Proniosomal Gel: Potential Carrier System in Transdermal Delivery for Non-Steroidal Anti-inflammatory Drugs (NSAID). Int J Pharm Life Sci. 2014;5(10):3939-47.

8. Tamizharasi S, Dubey A, Rathi V, Rathi JC. Development and Characterization of Niosomal Drug Delivery of Gliclazide. J Young Pharm. 2009;1(3):205-9.

9. Samy AM, Ghorab MM, Shadeed SG, Mazyed EA. Formulation and evaluation of differefnt transdermal drug delivery systems of ketoprfen. Int J Pharm Pharm Sci. 2013;5(2):600-7.

10. Sammour OA, Marzouk MA, Ramadan AA, Shawky SM. In-vitro permeation and pharmaco-dynamic properties of gel formulations containing tenoxicam entrapped niosomes. J Life Med. 2013;1(1):1-10.

11. Ibrahim MM, Hafez SA, Mahdy MA. Organogels, hydrogels and bigels as transdermal delivery systems for diltiazem hydrochloride. Asian J Pharm Sci. 2013;8(1):48-57.

12. Ramkanth S, Chetty CM, Sudhakar Y. Development and in-vitro permeation studies of proniosomal based transdermal delivery system of atenolol. Pak J Pharm Sci. 2014;27(1):115-20

13. Abdallah MH, Sammour OA, EL-Ghamry HA, Abu-Selem ME. Preparation and in-vitro evaluation of diclofenac sodium niosomal formulations. Int J Pharm Sci Res. 2013;4(5):1757-65.

14. Rajaram K. Antioxidant and antidiabetic activity of tectona grandis linn in alloxan induced albino rats. Asian J Pharm Clin Res. 2013;6(3):174-7.

15. Kumawat NS, Chaudhari SP,Wani NS, DeshmukhTA, Patil VR. Antidiabetic activity of ethanol extract of Colocasia esculenta leaves in alloxan induced diabetic rats. Int J Pharm Tech Res. 2010;2(2):1246-9.

16. Haritha C, Reddy AG, Reddy YR, AnjaneyuluY, Rao TM, Kumar BA, Kumar MU. Evaluation of protective action of fenugreek, insulin and glimepiride and their combination in diabetic Sprague Dawley rats. J Nat Sci Biol Med. 2013;4(1):207-12

17. Kibbe AH. 2000. Handbook of Pharmaceutical Excepients, $3^{\text {rd }}$ ed. American Pharmaceutical Association: Washington: DC, 511-14.

18. Ibrahim MMA, Sammour OA, Hammad MA, Megrab NA. In-vitro evaluation of proniosomes as a drug carrier for flurbiprofen. AAPS Pharm Sci Tech. 2008; 9(3):782-90.

19. Mohawed OAM, El-Ashmoony MM, Elgazayerly ON. Niosome-encapsulated clomipramine for transdermal controlled delivery. Int J Pharm Pharm Sci. 2014;6(9):567-75.

20. Guinedi AS, Mortada ND, Mansour S, Hathout RM. Preparation and evaluation of reverse-phase evaporation and multilamellar niosomes as ophthalmic carriers of acetazolamide. Int J Pharm. 2005;306(1):71-82.

21. Rawat AS, Kumar MS, Khurana B, Mahadevan N. Proniosome Gel: A NovelTopical Delivery System. Int J Rec Adv Pharm Res. 2011;3(1):1-10.

22. YoshiokaT, Sternberg B, Florence AT. Preparation and properties of vesicles (niosomes) of sorbitan monoesters (Span 20,40, 60 and 80) and sorbitan triesters (Span 85). Int J Pharm. 1994;105(1):1-6.

23. Shehata TM, Abdallah MH, Ibrahim MM. Proniosomal Oral Tablets for Controlled Delivery and Enhanced Pharmacokinetic Properties of Acemetacin. AAPS Pharm Sci Tech. 2015; 16(2):375-80.

24. Abdallah $\mathrm{MH}$. Transfersomes as a transdermal drug delivery system for enhancement the antifungal activity of nystatin. Int J Pharm Pharm Sci. 2013;5(4):560-7.

25. El Maghraby GM, Ahmed AA, Osman MA. Skin delivery of nisoldipine from niosome proconcentrate. J App Pharm Sci. 2014;4(02):112-7.

26. Shilpa S, Srinivasan BP, Chauhan M. Niosomes as vesicular carriers for delivery of proteins and biologicals. Int J Drug Deliv. 2011;3(1):14-24.

27. Thakur R, Anwer MK, Shams MS, Ali A, Khar RK, Shakee S, et al. Proniosomal transdermal therapeutic system of losartan potassium: development and pharmacokinetic evaluation. J Drug Targ. 2009;17(6):442-9.

28. Munish G, Parul G. Encapsulation of bio-active compound ursolic acid as proniosomes and its evaluation. Asian J Pharm. 2013:7(4):158-62. 